\title{
A Comparative Study of Sagittal Spinal-Pelvic Parameters Between Patients with Adolescent Idiopathic Scoliosis and Healthy Controls
}

\author{
Un Estudio Comparativo de los Parámetros Sagitales de la Columna Vertebral-Pélvic \\ Entre Pacientes Adolescentes con Escoliosis idiopática y Controles Sanos
}

Cong Zhang'; Yunfeng Zhang²; Lidong Wang'; Jinghong Yu²; Yan Zhao²; Huifeng Sun²; Haiyan Wang'; Baoke Su; Shang Gao ${ }^{1}$; Jianzhong Wang ${ }^{1}$; Xing Wang ${ }^{1}$; Yongqiang Cai ${ }^{1}$; Enhe Jirigala ${ }^{1}$; Yangyang Xu ${ }^{1}$; Zhiqiang Wang ${ }^{1}$; Mingjie Gao ${ }^{1}$; Zhijun $\mathrm{Li}^{1}$; Wei Wang ${ }^{4} \&$ Xiaohe $\mathbf{L i}^{1}$

ZHANG, C.; ZHANG, Y.; WANG, L.; YU, J.; ZHAO, Y.; SUN, H.; WANG, H.; SU, B.; GAO, S.; WANG, J.; WANG, X.; CAI, Y.; JIRIGALA, E.; XU, Y.; WANG, Z.; GAO, M.; LI, Z.; WANG, W. \& LI, X. A comparative study of sagittal spinal-pelvic parameters between patients with adolescent idiopathic scoliosis and healthy controls. Int. J. Morphol., 38(2):415-422, 2020.

SUMMARY: This study aimed to investigate the sagittal spinal-pelvic morphological changes, as well as the relationship between pelvic anatomical changes and the spinal-pelvic plane in patients with adolescent idiopathic scoliosis (AIS), in order to provide guidelines for orthopedic surgery in AIS. X-ray data were collected for retrospective analysis from 30 patients diagnosed as AIS in the Departments of Radiology at the Second Affiliated Hospital of Inner Mongolia Medical University and the Inner Mongolia International Mongolian Medical Hospital from April 2014 to November 2018, along with 30 normal adolescents as control. Pelvic parameters, including pelvic incidence (PI), pelvic tilt (PT), and sacral slope (SS), a spinal parameter, lumbar lordosis (LL), and anatomical parameters, including sacral width (SW) and femoral head- sacrum distance (FH-S), were measured. The spinal-pelvic parameters were compared between AIS patients and normal controls and also between male and female AIS patients. Pearson correlation was performed to analyze correlation between spinal-pelvic parameters and between spinal-pelvic parameters and anatomical parameters in both AIS patients and normal controls. PT was significantly lower in AIS patients than in normal controls $(\mathrm{P}<0.05)$, whereas no significant difference was found in the other spinal-pelvic parameters, i. e. , LL, PI, and SS. There was a significant difference in PT between sexes in AIS patients. SS was significantly correlated with LL in EIA patients ( $\mathrm{P}<0.05, \mathrm{r}>0.5)$. SS was significantly correlated with LL and PI, and PT with LL, PI, and SS in normal controls (all $\mathrm{P}<0.05)$, and there was no significant correlation between the other sagittal spinal-pelvic parameters $(\mathrm{P}$ $>0.05$ ). FH-S was significantly correlated with LL, PI, SS, and PT in AIS patients (all P < 0.05). AIS affects some of the sagittal spinalpelvic parameters and anatomical parameters. In AIS, there is a significant correlation between the spinal-pelvic parameters, and the anatomical parameter is significantly correlated with multiple spinal-pelvic parameters.

KEY WORDS: Idiopathic scoliosis; Adolescent; Spinal-pelvic parameters; Digital measurement.

\section{INTRODUCTION}

Idiopathic scoliosis (Wajchenberg et al., 2015; Skibinska et al., 2016) usually first appears around the time of puberty, with a different peak age of incidence between sexes. It is mainly manifested as coronal scoliosis, reduced sagittal kyphosis, and three-dimensional malformation of horizontal vertebral rotation (Weinstein et al., 2013), affecting 0.5-3\% of adolescents (Hresko et al., 2013; Zapata et al., 2015). The standing posture of the human body is jointly determined by the spine curve and the pelvis. The pelvis not only serves as the basis of the load carrying capacity of the spine, but also constitutes an important mechanical hub of the human body with the lower lumbar vertebrae. Changes in spinal-pelvic morphology and orientation are one of the causes of idiopathic scoliosis.

Extensive studies have been performed on the relationship between coronal imbalance and spinal-pelvic parameters in adult spinal deformity (Kong et al., 2016).

${ }^{1}$ Inner Mongolia Medical University, Inner Mongolia Huhhot010010, P. R. China.

${ }^{2}$ Department of CT center, The second affiliated hospital of Inner Mongolia Medical University Huhhot 010110,Inner Mongolia, P. R. China.

${ }^{3}$ Department of CT center, Inner Mongolia international Mongolian hospital,Huhhot 010000,Inner Mongolia, P. R. China.

${ }^{4}$ Department of Emergency, Inner Mongolia People's Hospital, Hohhot 010017, P. R. China.

Cong Zhang and Yunfeng Zhang are equal contribution to papers. 
ZHANG, C.; ZHANG, Y.; WANG, L.; YU, J.; ZHAO, Y; SUN, H.; WANG, H.; SU, B.; GAO, S.; WANG, J.; WANG, X.; CAI, Y.; JIRIGALA, E.; XU, Y.; WANG, Z.; GAO, M.; LI, Z.; WANG, W. \& LI, X. A comparative study of sagittal spinal-pelvic parameters between patients with adolescent idiopathic scoliosis and healthy controls. Int. J. Morphol., 38(2):415-422, 2020.

However, there are few studies comparing spinal-pelvic parameters and sagittal spinal-pelvic morphology between patients with adolescent idiopathic scoliosis (AIS) and normal adolescents. In this regard, this study intends to investigate the changes in and correlation between spinal-pelvic parameters in AIS patients, in order to provide reference data for adolescent spinal orthopedics and provide guidelines for clinical practice to reduce symptoms and improve quality of life (Schwab et al., 2010).

\section{MATERIAL AND METHOD}

General information. Thin section X-ray (anterior-posterior and lateral) data were collected for retrospective analysis from patients with Lenke 2 AIS, with a Cobb angle of $\angle 80^{\circ}$, in the Departments of Radiology at the Second Affiliated Hospital of Inner Mongolia Medical University and the Inner Mongolia International Mongolian Medical Hospital from April 2014 to November 2018 (Wang et al., 2017).

All patients were diagnosed by chief physicians of orthopedics and spine surgery at both hospitals. A total of 54 patients were screened and 30 were enrolled, including 13 males and 17 females, aged 12-18 years, with an average of 15.1 years. The control group was comprised of 30 normal adolescents, including 15 males and 15 females, aged 12-18 years, with an average of 15.2 years. Exclusion criteria: (1) spinal trauma or deformity; (2) a history of spine, pelvis, or other surgery that may affect the spinal-pelvic parameters; (3) pelvic deformity, unequal length of lower limbs, or any condition that may affect measurements; and (4) imaging data indicating significant neurological symptoms and signs.

Imaging measurements. Anteroposterior and lateral X-ray films were taken from all patients in standing position with hands on the lower jaw, eyes looking straight, and hip joints fully extended. Pelvic incidence (PI), sacral slope (SS), pelvic tilt (PT), lumbar lordosis (LL), sacral width (SW), and femoral head- sacrum distance (FH-S) were measured on the lateral radiograph as follows:

(1) PI was measured as the angle between a line perpendicular to the superior endplate of sacrum 1 (S1) at its midpoint and a line connecting this point to the center of the femoral heads. If the femoral heads did not overlap in the radiograph, the midpoint of the line connecting the center of the femoral head was taken as a reference point (Fig. 1).

(2) SS was measured as the angle between the superior endplate of S1 and the horizontal line (Fig. 2).

(3) PT was measured as the angle between the line connecting the midpoint of the superior endplate of S1 and the center of the femoral head and the vertical line (Fig. 3).

(4) LL was measured as the angle between the upper edges of lumbar 1 (L1) and S1 (Fig. 4).

(5) SW was defined as the distance between the lowest points of the sacroiliac joints (Fig. 5).

(6) FH-S was the distance between the center of the femoral heads and the vertical line passing through the posterosuperior corner of S1 (Fig. 6).

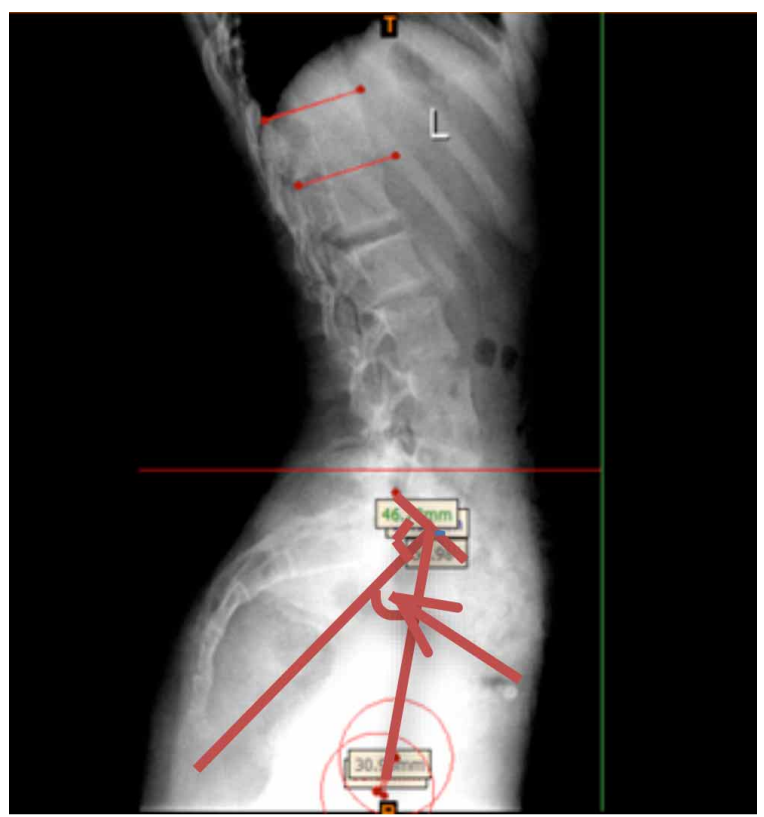

Fig. 1. Pelvic incidence.

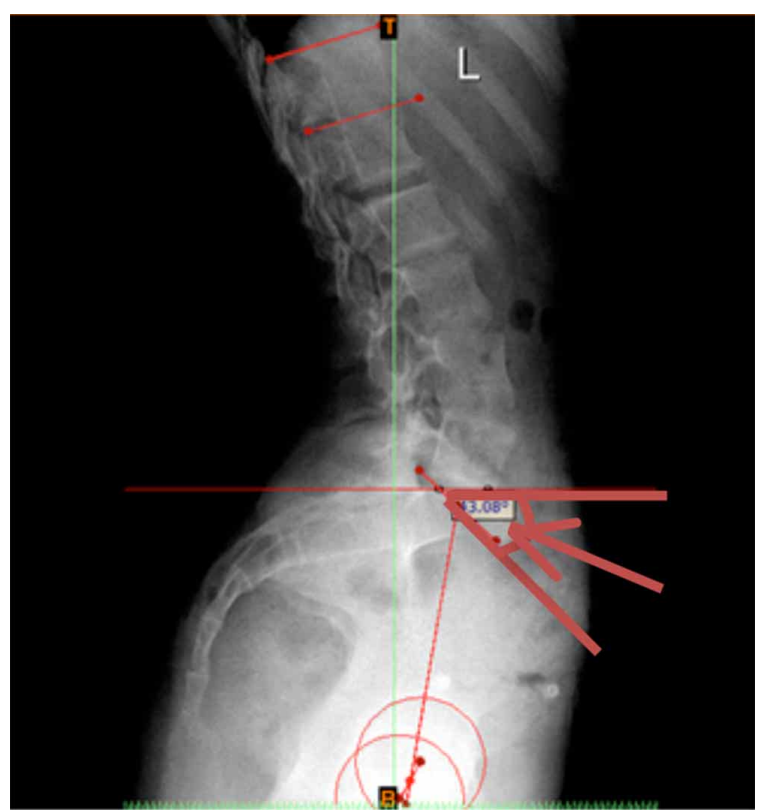

Fig. 2. Sacral slope. 


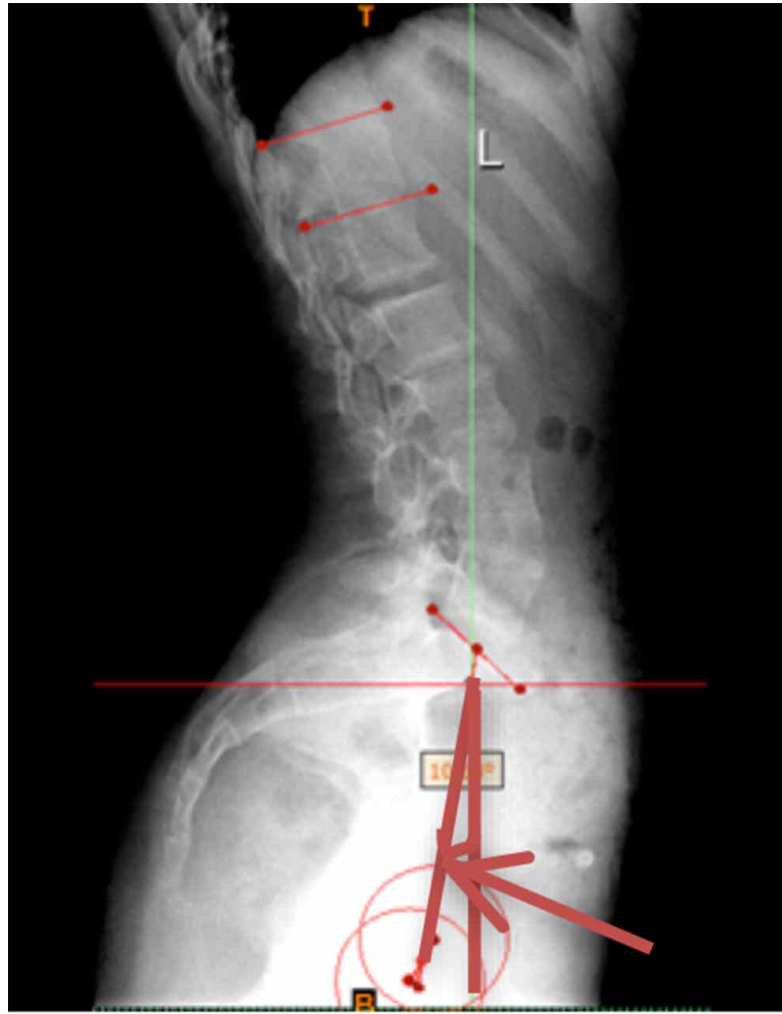

Fig. 3. Pelvic tilt.

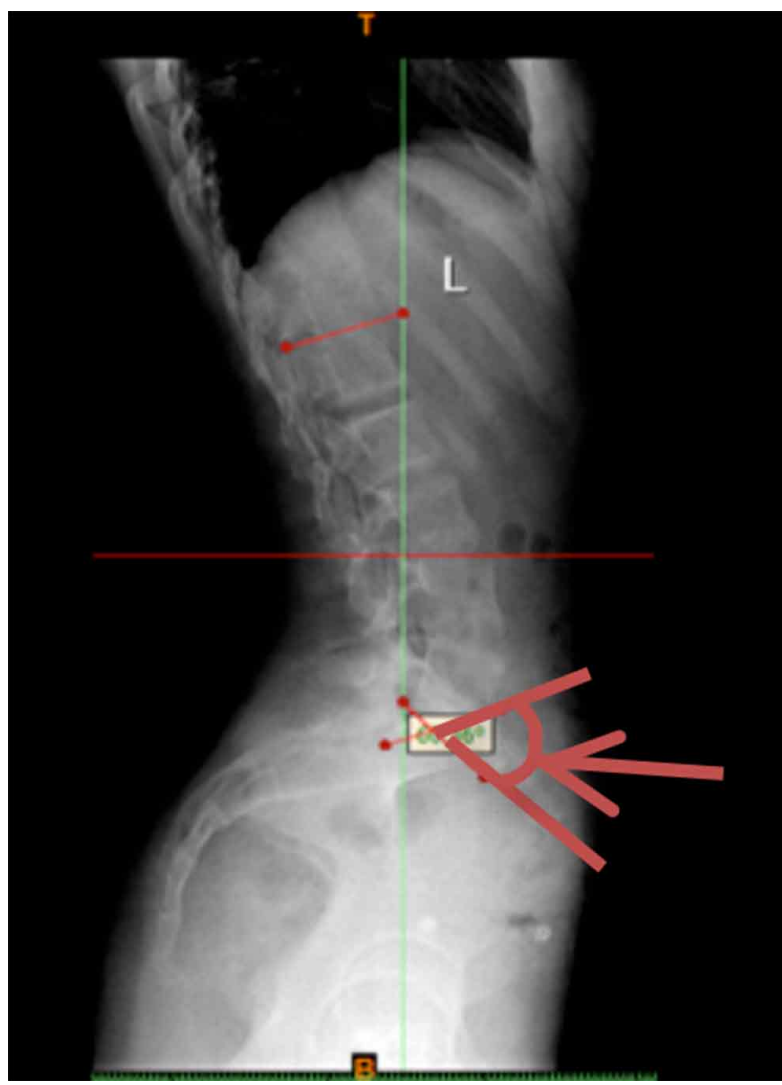

Fig. 4. Lumbar lordosis.

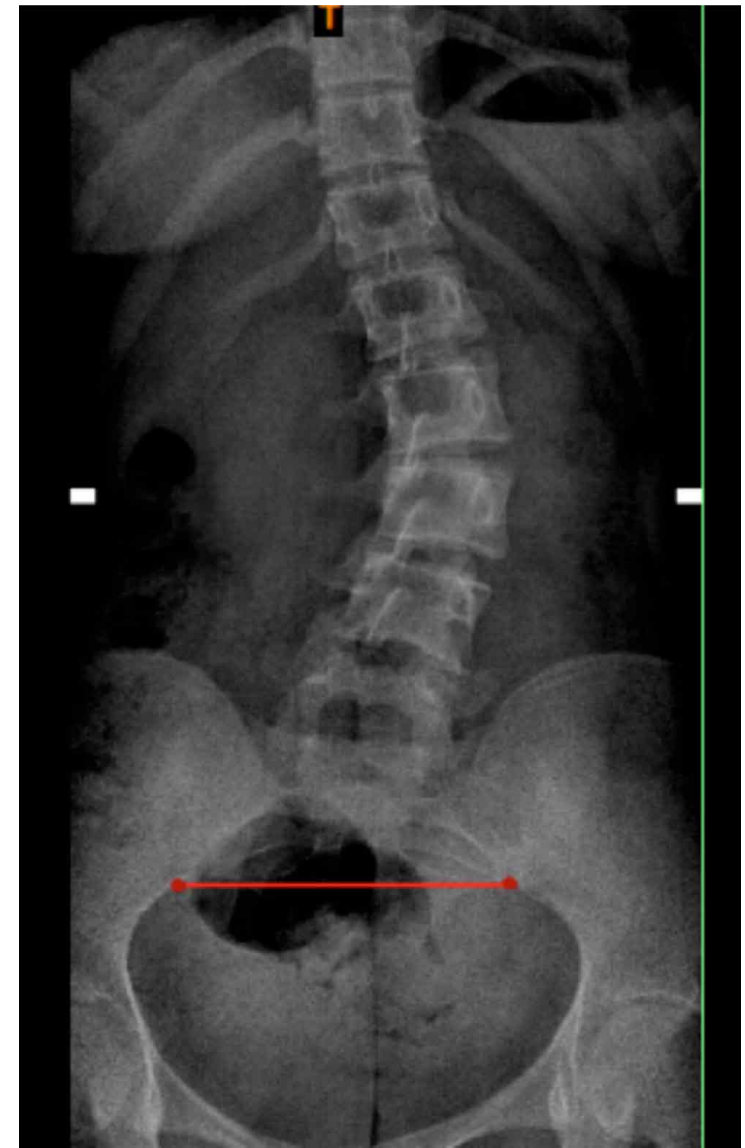

Fig. 5. Sacral width.

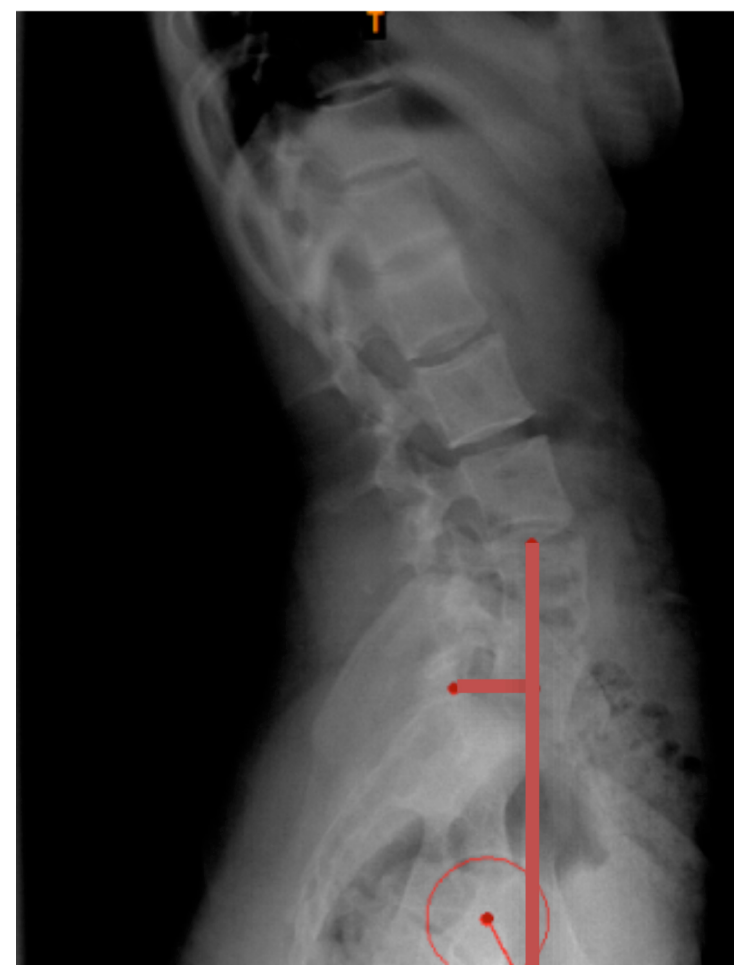

Fig. 6. Femoral head-sacrum. 
ZHANG, C.; ZHANG, Y.; WANG, L.; YU, J.; ZHAO, Y; SUN, H.; WANG, H.; SU, B.; GAO, S.; WANG, J.; WANG, X.; CAI, Y.; JIRIGALA, E.; XU, Y.; WANG, Z.; GAO, M.; LI, Z.; WANG, W. \& LI, X. A comparative study of sagittal spinal-pelvic parameters between patients with adolescent idiopathic scoliosis and healthy controls. Int. J. Morphol., 38(2):415-422, 2020.

Statistical analysis. The above parameters were measured twice by the same examiner, and the mean of two measurements was used. The data were statistically analyzed using SPSS 23. 0. First, descriptive analysis was performed to obtain the maximum, minimum, average, and standard deviation for each sagittal parameter of AIS patients and normal controls. An independent sample t-test was also used to compare each parameter between the two groups $(\mathrm{P}<$ 0.05 was considered statistically significant). Second, the effect of sex on the spinal-pelvic parameters of AIS patients was investigated. Finally, Pearson correlation coefficient was used to analyze the bivariate correlation between each parameter $(\mathrm{P}<0.05$ was considered statistically significant; $\mathrm{r}=0-0.1$ indicates no correlation; $\mathrm{r}=0.1-0.3$ indicates a small correlation; $r=0.3-0.5$ indicates a medium correlation; and $r=0.5-1$ indicates a large correlation).

\section{RESULTS}

General information. The age of subjects ranged from 12 to 18 years, with an average of $(15.24 \pm 1.92)$ years. The AIS group included 30 patients ( 13 males and 17 females), with an average age of 15.14 years. The control group included 30 healthy subjects (15 males and 15 females), with an average age of 15.33 years.

Sagittal spinal-pelvic parameters and pelvic anatomical parameters of AIS patients and normal controls. LL was measured to be $49.7 \pm 8.3^{\circ}$, PI $41.9 \pm 9.7^{\circ}$, SS $34.4 \pm 8.1^{\circ}$, PT $10.4 \pm 4.5^{\circ}$, SW $8.8 \pm 0.7^{\circ}$, and FH-S $2.6 \pm 1.1^{\circ}$ in AIS patients. In normal controls, LL was measured to be $41.3 \pm$ $12.5^{\circ}$, PI $48.7 \pm 8.2^{\circ}$, SS $32.1 \pm 8.1^{\circ}$, PT $15.8 \pm 7.7^{\circ}$, SW 9.4 $\pm 0.7^{\circ}$, and FH-S $3.4 \pm 1.3^{\circ}$. According to the independent sample t-test, $\mathrm{PT}, \mathrm{SW}$, and FH-S were significantly lower in AIS patients than in normal controls (all $\mathrm{P}<0.05$ ), whereas there was no significant difference in LL, PI, and SS (P > 0.05). It indicates that AIS has a great impact on PT, SW, and FH-S (Table I).

Comparison of spinal-pelvic parameters and pelvic anatomical parameters between sexes in AIS patients. LL was measured to be $47.3 \pm 6.9^{\circ}$ in male and $51.6 \pm 9.9^{\circ}$ in female; PI was measured to be $47.7 \pm 7.7^{\circ}$ in male and $37.3 \pm 8.8^{\circ}$ in female; $\mathrm{SS}$ was measured to be $34.3 \pm 7.0^{\circ}$ in

Table I. Comparison of spine-pelvic parameters and pelvic anatomical parameters between AIS patients and normal adolescents.

\begin{tabular}{lllllcccc}
\hline & Type & Cases & Max & Min & Average & $\begin{array}{c}\text { Standard } \\
\text { deviation }\end{array}$ & F & P \\
\hline LL & AIS & 30 & 34.01 & 65.40 & 49.6941 & 8.82857 & 3.874 & 0.054 \\
& Normal & 30 & 17.42 & 65.30 & 41.3160 & 12.46863 & & \\
PI & AIS & 30 & 22.30 & 59.15 & 41.8703 & 9.71575 & 1.559 & 0.217 \\
& Normal & 30 & 38.35 & 76.31 & 48.7480 & 8.21930 & & \\
SS & AIS & 30 & 18.95 & 47.42 & 34.3667 & 8.10291 & 0.003 & 0.954 \\
& Normal & 30 & 16.08 & 50.07 & 32.0903 & 8.10684 & & \\
PT & AIS & 30 & 4.38 & 21.82 & 10.4193 & 4.52828 & 5.963 & 0.018 \\
& Normal & 30 & 1.41 & 35.36 & 15.7970 & 7.67629 & & \\
SW & AIS & 30 & 7.12 & 10.23 & 8.8243 & 0.74373 & 0.000 & 0.002 \\
& Normal & 30 & 8.19 & 10.85 & 9.4550 & 0.73866 & & \\
FH-S & AIS & 30 & 0.24 & 5.49 & 2.6263 & 1.12226 & 0.890 & 0.014 \\
& Normal & 30 & 0.95 & 5.84 & 3.4347 & 1.34023 & & \\
\hline
\end{tabular}

Table II. Comparison of spine-pelvic parameters and pelvic anatomical parameters between different sexes in AISdifferent sexes in AIS

\begin{tabular}{|c|c|c|c|c|c|c|c|c|}
\hline & Sex & Cases & Max & Min & Average & $\begin{array}{l}\text { Standard } \\
\text { deviation }\end{array}$ & $\mathrm{F}$ & $\mathrm{P}$ \\
\hline \multirow[t]{2}{*}{ LL } & Male & 13 & 34.01 & 57.48 & 47.3208 & 6.86407 & 2.807 & 0.105 \\
\hline & Female & 17 & 35.00 & 65.40 & 51.6225 & 9.94757 & & \\
\hline \multirow[t]{2}{*}{ PI } & Male & 13 & 32.86 & 59.15 & 47.7408 & 7.74785 & 0.491 & 0.489 \\
\hline & Female & 17 & 22.30 & 53.84 & 37.3812 & 8.75547 & & \\
\hline \multirow[t]{2}{*}{ SS } & Male & 13 & 24.36 & 45.45 & 34.2946 & 6.99283 & 1.564 & 0.221 \\
\hline & Female & 17 & 18.95 & 47.42 & 34.4218 & 9.07311 & & \\
\hline \multirow[t]{2}{*}{ PT } & Male & 13 & 5.43 & 21.82 & 12.1608 & 5.47200 & 7.244 & 0.012 \\
\hline & Female & 17 & 4.38 & 15.84 & 9.0876 & 3.21878 & & \\
\hline \multirow[t]{2}{*}{ SW } & Male & 13 & 7.12 & 9.78 & 8.6515 & 0.81966 & 1.363 & 0.273 \\
\hline & Female & 17 & 7.64 & 10.23 & 8.9565 & 0.67518 & & \\
\hline \multirow[t]{2}{*}{ FH-S } & Male & 13 & 1.87 & 5.49 & 3.0531 & 1.09818 & 0.004 & 0.068 \\
\hline & Female & 17 & 0.24 & 4.08 & 2.3000 & 1.05695 & & \\
\hline
\end{tabular}


ZHANG, C.; ZHANG, Y.; WANG, L.; YU, J.; ZHAO, Y; SUN, H.; WANG, H.; SU, B.; GAO, S.; WANG, J.; WANG, X.; CAI, Y.; JIRIGALA, E.; XU, Y.; WANG, Z.; GAO, M.; LI, Z.; WANG, W. \& LI, X. A comparative study of sagittal spinal-pelvic parameters between patients with adolescent idiopathic scoliosis and healthy controls. Int. J. Morphol., 38(2):415-422, 2020.

male and $34.4 \pm 9.1^{\circ}$ in female; PT was measured to be 12.2 $\pm 5.5^{\circ}$ in male and $9.1 \pm 3.2^{\circ}$ in female; $\mathrm{SW}$ was measured to be $8.7 \pm 0.8^{\circ}$ in male and $9.0 \pm 0.7^{\circ}$ in female; and $\mathrm{FH}-\mathrm{S}$ was measured to be $3.1 \pm 1.1^{\circ}$ in male and $2.3 \pm 1.1^{\circ}$ in female. It can be seen that PT was significantly lower in female than in male AIS patients $(\mathrm{P}<0.05)$; in other words, the pelvic parameter, PT, was affected by sex. (Table II).

Correlation between sagittal vertebral-pelvic morphological parameters in AIS patients and normal controls. LL was positively correlated with SS in both AIS patients $(\mathrm{r}=0.803, \mathrm{P}<0.05)$ and normal controls $(\mathrm{r}=0.790, \mathrm{P}$ $<0.05)$. Moreover, in normal controls, PT was linearly correlated with LL ( $\mathrm{r}=-0.557, \mathrm{P}=0.004), \mathrm{PI}(\mathrm{r}=0.416, \mathrm{P}=0$. $022)$, and $\mathrm{SS}(\mathrm{r}=-0.492, \mathrm{P}=0.06)$; and there was also a correlation between PI and SS $(r=0.555, \mathrm{P}=0.01)$ (Table III).

\section{Correlation between spinal-pelvic parameters and pelvic} anatomical parameters in AIS patients and normal controls. The anatomical parameter, FH-S, was significantly correlated with the spinal-pelvic parameters, LL, PI, SS, and $\mathrm{PT}$, in AIS patients (all $\mathrm{P}<0.05$ ). Moreover, there was a significant correlation between FH-S and PT in normal controls $(\mathrm{P}<0.05)$. It suggests that the horizontal distance between the femoral head and sacrum has a great impact on the spinal-pelvic parameters (Table IV).

Table III. Correlation coefficient between spine-pelvic parameters of pelvic anatomical parameters of AIS patients and normal adolescents

\begin{tabular}{cllc}
\hline Type & $\begin{array}{c}\text { Pearson } \\
\text { correlation }\end{array}$ & $\begin{array}{c}\text { Pearson significance } \\
\text { (double-tailed) }\end{array}$ \\
\hline LL-PI & AIS & -0.030 & 0.878 \\
& Normal & 0.289 & 0.161 \\
LL-SS & AIS & $0.803 * *$ & 0.000 \\
& Normal & $0.790^{* *}$ & 0.000 \\
LL-PT & AIS & -0.248 & 0.195 \\
& Normal & $-0.557 * *$ & 0.004 \\
PI-SS & AIS & 0.305 & 0.101 \\
& Normal & $0.555^{* *}$ & 0.001 \\
PI-PT & AIS & 0.340 & 0.066 \\
& Normal & $0.416^{*}$ & 0.022 \\
PT-SS & AIS & -0.148 & 0.436 \\
& Normal & $-0.492^{* *}$ & 0.006 \\
\hline
\end{tabular}

** Correlation is significant at the 0.01 level (2-tailed)

\section{DISCUSSION}

AIS is a three-dimensional (coronal, sagittal, and transverse) deformity of the spine (Daubs et al., 2013). The spine and the pelvis jointly maintain the balance of the sagittal spinal-pelvic plan to assume an upright posture.
Table IV Correlation analysis between spine-pelvic parameters and pelvic anatomical changes in AIS and normal adolescents.

\begin{tabular}{clcc}
\hline TYPE & Pearson correlation & $\begin{array}{c}\text { Pearson significance } \\
\text { (double-tailed) }\end{array}$ \\
\hline LL-SW & AIS & 0.327 & 0.077 \\
& Normal & 0.185 & 0.377 \\
PI-SW & AIS & -0.154 & 0.417 \\
& Normal & -0.196 & 0.299 \\
SS-SW & AIS & 0.162 & 0.394 \\
& Normal & -0.029 & 0.880 \\
PT-SW & AIS & 0.263 & 0.161 \\
& Normal & -0.211 & 0.264 \\
LL-FH-S & AIS & $-0.559 * *$ & 0.001 \\
& Normal & -0.210 & 0.314 \\
PI-FH-S & AIS & $-0.386^{* *}$ & 0.035 \\
& Normal & 0.160 & 0.398 \\
SS-FH-S & AIS & $-0.443 * *$ & 0.014 \\
& Normal & -0.292 & 0.118 \\
PT-FH-S & AIS & $0.580^{* *}$ & 0.001 \\
& Normal & $0.596^{* *}$ & 0.001 \\
SW-FH-S & AIS & -0.104 & 0.586 \\
& Normal & -0.241 & 0.200
\end{tabular}

**Correlation is significant at the 0.01 level (2-tailed).

Spinal deformity leads to different degrees of compensatory imbalance of the sagittal spinal-pelvic plane (Ilharreborde et al., 2013), which can easily lead to imbalance of the body's center of gravity. This may be an important cause of low back pain in adolescents (Spanyer et al., 2015). Surgical treatment can correct the deformity, reconstruct the balance, prevent deformity progression, and significantly improve the quality of life of patients. Preoperative assessment of spinal-pelvic parameters and balance can help to find the least energy-consuming posture and reduce postoperative complications (Crawford et al., 2013).

Spinal-pelvic parameters and anatomical parameters in AIS patients and normal controls. PI is the main axis that controls and regulates the sagittal shape of the spine. Wafa et al., suggested that PI is a fundamental anatomical parameter of the pelvis, which can truly reflect the anatomy of the pelvis, does not change with the position, is not affected by subjective symptoms, and determines the relationship between the pelvis, tibia, and lumbar spine. PI varies with race (Zhu et al., 2014; Banno et al., 2016; Inami et al., 2016) and between individuals. It also changes with individual development. Specifically, PI remains relatively fixed in childhood, increases significantly in adolescence $\left(\mathrm{PI}=0.7436 \times\right.$ age $+39.561^{\circ}$ in adolescents older than 10 years), reaches a maximum in adults, and does not change significantly after maturation PI was measured to be $41.9 \pm 9.7^{\circ}$ in AIS patients with a mean age of $15.1 \pm 2.0$ years, which is lower than $55.5 \pm 12.2^{\circ}$ measured by Upasani et al. (2007) and $46.70 \pm 10.28^{\circ}(16.21 \pm 2.25$ 
ZHANG, C.; ZHANG, Y.; WANG, L.; YU, J.; ZHAO, Y; SUN, H.; WANG, H.; SU, B.; GAO, S.; WANG, J.; WANG, X.; CAI, Y.; JIRIGALA, E.; XU, Y.; WANG, Z.; GAO, M.; LI, Z.; WANG, W. \& LI, X. A comparative study of sagittal spinal-pelvic parameters between patients with adolescent idiopathic scoliosis and healthy controls. Int. J. Morphol., 38(2):415-422, 2020.

years) measured by Ye et al. (2016), but is close to $44.2 \pm 10^{\circ}$ (14.2 \pm 1.6 years) measured by Qiu et al. (Yong et al., 2012). This difference may be related to the age and race of patients. On the other hand, PI was measured to be $48.7 \pm 8.2^{\circ}$ in normal controls with a mean age of $15.2 \pm 1.9$ years, which is higher than $41.1 \pm 8.7^{\circ}$ measured by Wang et al. (2017), and $41.1^{\circ}-49.1^{\circ}$ measured by Duval-Beaupere et al. (Vaughn \& Schwend, 2014). There is a correlation between LL and PI. For example, Legaye et al., suggested that LL $\approx \mathrm{PI}+10^{\circ}$ in normal humans, that ideal LL can be roughly estimated based on known PI to obtain the information of global spinal balance, and that PI directly controls SS to increase LL. In idiopathic scoliosis, in order to prevent or limit the imbalance of the sagittal spinal-pelvic plane (Vaughn \& Schwend; Aykac et al., 2015), an upright posture is maintained by a compensatory increase in LL or pelvic retroversion.

PT is highly correlated with quality of life. In other words, the rebalance of the sagittal spinal-pelvic plane, especially the return of PT to normal, is critical for quality of life after orthopedic surgery for scoliosis (Wang et al., 2015). It can be seen from Table I that PT was significantly lower in AIS patients than in normal controls $\left(10.4 \pm 4.5^{\circ}\right.$ for $15.1 \pm$ 2.0 years vs. $15.8 \pm 7.7^{\circ}$ for $15.2 \pm 1.9$ years $)(\mathrm{P}<0.05)$. This is consistent with the conclusions of Wang et al. (2009) that the pelvis tilts backwards to compensate for spinal imbalance in patients with spinal deformity and that PT is a measure to evaluate compensation for spinal deformity. The sagittal spinalpelvic plane of AIS patients is characterized by a decrease in PT and pelvic retroversion. In healthy adolescents, the pelvis slightly tilts forward as the body's center of gravity shifts to the front of the spine due to the upright posture; and at the level of hip joint, the center of gravity should be located behind the hip joint and in front of the second sacral vertebra to counteract the forward tilt caused by gravity. In other words, in healthy adolescents, the sacrum is in a head-down position, the sacroiliac joint is closed, the pelvis and vertebrae are in a neutral position to maintain body balance. By contrast, in AIS patients, the sagittal spine-pelvis plane is out of balance, the sacrum is in a head-up position, and the pelvis tilts backward to maintain body balance.

This study found that an increase in SW increased the stability of the sacroiliac joint, thereby maintaining the spinal-pelvic balance. In AIS patients, SW was significantly lower than that in normal controls, and the sacroiliac joint was not closed, resulting in lumbar lordosis and decreased spinal-pelvic stability. Moreover, FH-S was significantly reduced. The reason for this may be that the acetabulum shifts forward during the pelvic growth, and the pelvis tilts backward as a compensatory response; and consequently, the sacrum is in a head-up position, and the position of the superior sacral endplate changes.
Comparison of spinal-pelvic parameters and pelvic anatomical parameters between sexes in AIS patients. Most studies suggest that there is no significant difference in spinal-pelvic parameters between sexes. However, the progression of AIS is related to puberty. The peak growth period is different between sexess. The growth peak occurs slightly earlier in female than in male. In this study, PT was measured to be $9.1 \pm 3.2^{\circ}$ in female AIS patients, which is significantly lower than $12.2 \pm 5.5^{\circ}$ in male $(\mathrm{P}<0.05)$. This may be related to the difference in the pelvic bone structure between sexes (Schlösser et al., 2014; Giacomini et al., 2015; Bao et al., 2018), a larger anteroposterior diameter of pelvic inlet and wider pubic arch in female, and a higher degree of sacral anteversion in male (Abola et al., 2018).

\section{Correlation between spinal-pelvic parameters in AIS} patients and normal controls. In this study, LL was significantly correlated with SS in AIS patients, and LL with SS, PT with LL, and PI with SS, PI and SS in normal controls. This finding is consistent with previous studies. The lumbar vertebrae and sacrum are connected by superior and inferior zygapophyseal joints, ligaments, and muscles. The sacrum is connected to the ilium by the sacroiliac joint and ligaments. Therefore, a tilted sacrum results in the changes of the lumbar vertebrae and pelvis. In other words, SS is positively correlated with LL and PI. It has been demonstrated that PI $=\mathrm{PT}+\mathrm{SS}$; that is, a higher PI indicates a tilted pelvis and a higher SS. Previous studies have also found that PI is associated with LL in adult scoliosis. PI can be considered as the core parameter for maintaining the balance of the sagittal spine-pelvis plane. PI was correlated with SS and PT. Specifically, in AIS patients, PI was reduced, and the pelvis tilted backward, which consequently altered the SS and PT, so that more weight was borne by the spinepelvis-lower limb to reduce muscle energy consumption and maintain body balance.

Limitations. First, due to the low incidence of AIS and limited collection time, the sample size was limited, which might induce errors in the spinal-pelvic measurements. Second, only the sagittal spine-pelvis parameters were investigated, whereas coronal and axial parameters were not analyzed. The relationship between the three planes is complicated. Further research is required in this regard. Finally, the results of this study are based on imaging data and need to be validated by long-term follow-up studies.

In summary, PT, SW, and FH-S were significantly lower in AIS patients than in normal controls (all $\mathrm{P}<0.05$ ); there was a difference in PT between sexes; LL was positively correlated with SS in AIS patients; LL was positively correlated with SS, PI with SS, PI with LL, and PI with PT in normal controls; and FH-S was positively correlated with LL, PI, SS, 
and PT in AIS patients. A comparative study of spinal-pelvic parameters between AIS patients and normal controls is instructive for improving quality of life and orthopedic surgery outcomes (Murphy \& Mooney 3rd, 2016; Kemppainen et al., 2016; Ohrt-Nissen et al., 2017), establishing sagittal spinalpelvic balance, and maintaining the least energy-consuming posture in patients with AIS.

ZHANG, C.; ZHANG, Y.; WANG, L.; YU, J.; ZHAO, Y; SUN, H.; WANG, H.; SU, B.; GAO, S.; WANG, J.; WANG, X.; CAI, Y.; JIRIGALA, E.; XU, Y.; WANG, Z.; GAO, M.; LI, Z.; WANG, W. \& LI, X. Estudio comparativo de los parámetros sagitales de la columna vertebral-pélvica entre pacientes adolescentes con escoliosis idiopática y controles sanos. Int. J. Morphol., 38(2):415-422, 2020.

RESUMEN: Este estudio tuvo como objetivo investigar los cambios morfológicos sagitales de la columna vertebral-pélvica, así como la relación entre los cambios anatómicos pélvicos y el plano espinal-pélvico en pacientes con escoliosis idiopática adolescente (EIA), con el fin de proporcionar pautas para la cirugía ortopédica en AIS. Se obtuvieron los datos de rayos X para el análisis retrospectivo de 30 pacientes diagnosticados como EIA en los Departamentos de Radiología del hospital Second Affiliated Hospital of Inner Mongolia Medical University y el hospital Inner Mongolia International Mongolian Medical Hospital, desde abril de 2014 hasta noviembre del 2018, junto con 30 adolescentes normales como control. Se midieron los parámetros pélvicos, que incluyeron incidencia pélvica (IP), inclinación pélvica (P) y pendiente sacra (PS), un parámetro espinal, lordosis lumbar (LL) y parámetros anatómicos, que incluyeron el ancho sacro (AS) y la distancia del sacro cabeza femoral (FH-S). Los parámetros espinalpélvicos se compararon entre los pacientes con EIA y los controles normales, como también entre pacientes con EIA masculinos y femeninos. La correlación de Pearson se realizó para analizar la correlación entre los parámetros espinal-pélvicos y entre los parámetros espinal-pélvicos y los parámetros anatómicos tanto en pacientes con EIA como en controles normales. PT fue significativamente menor en pacientes con EIA que en los controles normales $(\mathrm{P}<0,05)$, mientras que no se encontraron diferencias significativas en los otros parámetros espinal-pélvicos, i. mi. , LL, PI y SS. Hubo una diferencia significativa en PT en pacientes de ambos sexos con EIA. SS se correlacionó significativamente con LL en pacientes con EIA (P $<0,05, r>0,5)$. SS se correlacionó significativamente con LL y PI, y PT con LL, PI y SS en controles normales (todos P $<0,05$ ), y no hubo correlación significativa entre los otros parámetros sagitales de la columna vertebral-pélvica (P>0,05) FH-S se correlacionó significativamente con LL, PI, SS y PT en pacientes con EIA (todos $\mathrm{P}<0,05)$. EIA afecta algunos de los parámetros sagitales de la columna vertebral-pélvica y los parámetros anatómicos. En EIA, existe una correlación significativa entre los parámetros espinal-pélvicos, y el parámetro anatómico se correlaciona significativamente con múltiples parámetros espinales-pélvicos.

PALABRAS CLAVE: Escoliosis idiopática; Adolescente; Parámetros espinal-pélvicos; Medición digital.

\section{REFERENCES}

Abola, M. V.; Teplensky, J. R.; Cooperman, D. R.; Bauer, J. M. \& Liu, R. W. Pelvic incidence is associated with sacral curvature, sacroiliac joint angulation, and sacral ala width. Spine (Phila Pa 1976), 43(22):152935, 2018.

Aykac, B.; Ayhan, A.; Yuksel, S.; Guler, U. O.; Pellise, F.; Alanay, A.; PerezGrueso, F. J. S.; Acaroqlu, E. \& ESSG European Spine Study Group. Sagittal alignment of cervical spine in adult idiopathic scoliosis. Eur. Spine J., 24(6):1175-82, 2015.

Banno, T.; Togawa, D.; Arima, H.; Hasegawa, T.; Yamato, Y.; Kobayashi, S.; Yasuda, T.; Oe, S.; Hoshino, H. \& Matsuyama, Y. The cohort study for the determination of reference values for spinopelvic parameters (T1 pelvic angle and global tilt) in elderly volunteers. Eur. Spine J., 25(11):3687-93, 2016.

Bao, H.; Liabaud, B.; Varghese, J.; Lafage, R.; Diebo, B. G.; Jalai, C.; Ramchandran, S.; Poorman, G.; Errico, T.; Zhu, F.; et al. Lumbosacral stress and age may contribute to increased pelvic incidence: an analysis of 1625 adults. Eur. Spine J., 27(2):482-8, 2018.

Crawford, A. H.; Lykissas, M. G.; Gao, X.; Eismann, E. \& Anadio, J. Allpedicle screw versus hybrid instrumentation in adolescent idiopathic scoliosis surgery: a comparative radiographical study with a minimum 2-year follow-up. Spine (Phila Pa 1976), 38(14):1199-208, 2013.

Daubs, M. D.; Lenke, L. G.; Bridwell, K. H.; Kim, Y. J.; Hung, M.; Cheh, G. \& Koester, L. A. Does correction of preoperative coronal imbalance make a difference in outcomes of adult patients with deformity? Spine (Phila Pa 1976), 38(6):476-83, 2013.

Giacomini, S.; Di Silvestre, M.; Lolli, F.; Vommaro, F.; Martikos, K.; Maredi, E.; Baioni, A. \& Greggi, T. Is there a correlation between pelvic incidence and proximal junctional kyphosis (PJK) after surgery for adult scoliosis? Scoliosis, 10(Suppl. 1):O53, 2015.

Hresko, M. T. Idiopathic scoliosis in adolescents. N. Engl. J. Med., 368(9):834-41, 2013.

Ilharreborde, B.; Vidal, C.; Skalli, W. \& Mazda, K. Sagittal alignment of the cervical spine in adolescent idiopathic scoliosis treated by posteromedial translation. Eur. Spine J., 22(2):330-7, 2013.

Inami, S.; Moridaira, H.; Takeuchi, D.; Shiba, Y.; Nohara, Y. \& Taneichi, H. Optimum pelvic incidence minus lumbar lordosis value can be determined by individual pelvic incidence. Eur. Spine J., 25(11):363843, 2016.

Kemppainen, J. W.; Morscher, M. A.; Gothard, M. D.; Adamczyk, M. J. \& Ritzman, T. F. Evaluation of limited screw density pedicle screw constructs in posterior fusions for adolescent idiopathic scoliosis. Spine Deform., 4(1):33-9, 2016.

Kong, L. D.; Zhang, Y. Z.; Wang, F.; Kong, F. L.; Ding, W. Y. \& Shen, Y. Radiographic restoration of sagittal spinopelvic alignment after posterior lumbar interbody fusion in degenerative spondylolisthesis. Clin. Spine Surg., 29(2):E87-92, 2016.

Murphy, R. F. \& Mooney 3rd, J. F. Complications following spine fusion for adolescent idiopathic scoliosis. Curr. Rev. Musculoskelet. Med., 9(4):462-9, 2016.

Ohrt-Nissen, S.; Hallager, D. W.; Karbo, T.; Gehrchen, M. \& Dahl, B. Radiographic and functional outcome in adolescent idiopathic scoliosis operated with hook/hybrid versus all-pedicle screw instrumentation-A retrospective study in 149 patients. Spine Deform., 5(6):401-8, 2017.

Schlösser, T. P.; Janssen, M. M. A.; Vrtovec, T.; Pernus, F.; Oner, F. C.; Viergever, M. A.; Vincken, K. L. \& Castelein, R. M. Evolution of the ischio-iliac lordosis during natural growth and its relation with the pelvic incidence. Eur. Spine J., 23(7):1433-41, 2014.

Schwab, F.; Patel, A.; Ungar, B.; Farcy, J. P. \& Lafage, V. Adult spinal deformity-postoperative standing imbalance: how much can you tolerate? An overview of key parameters in assessing alignment and planning corrective surgery. Spine (Phila Pa 1976), 35(25):2224-31, 2010. 
ZHANG, C.; ZHANG, Y.; WANG, L.; YU, J.; ZHAO, Y; SUN, H.; WANG, H.; SU, B.; GAO, S.; WANG, J.; WANG, X.; CAI, Y.; JIRIGALA, E.; XU, Y.; WANG, Z.; GAO, M.; LI, Z.; WANG, W. \& LI, X. A comparative study of sagittal spinal-pelvic parameters between patients with adolescent idiopathic scoliosis and healthy controls. Int. J. Morphol., 38(2):415-422, 2020.

Skibinska, I.; Tomaszewski, M.; Andrusiewicz, M.; Urbaniak, P.; CzarneckaKlos, R.; Shadi, M.; Kotwicki, T. \& Kotwicka, M. Expression of estrogen receptor coactivator Proline-, Glutamic acid- and Leucinerich Protein 1 within paraspinal muscles in adolescents with idiopathic scoliosis. PLoS One, 11(4):e0152286, 2016.

Spanyer, J. M.; Crawford 3rd, C. H.; Canan, C. E.; Burke, L. O.; Heintzman, S. E. \& Carreon, L. Y. Health-related quality-of-life scores, spine-related symptoms, and reoperations in young adults 7 to 17 years after surgical treatment of adolescent idiopathic scoliosis. Am. J. Orthop. (Belle Mead NJ), 44(1):26-31, 2015.

Upasani, V. V.; Tis, J.; Bastrom, T.; Pawelek, J.; Marks, M.; Lonner, B.; Crawford, A. \& Newton, P. O. Analysis of sagittal alignment in thoracic and thoracolumbar curves in adolescent idiopathic scoliosis: how do these two curve types differ? Spine (Phila Pa 1976), 32(12):1355-9, 2007.

Vaughn, J. J. \& Schwend, R. M. Sitting sagittal balance is different from standing balance in children with scoliosis. J. Pediatr. Orthop., 34(2):202-7, 2014.

Wajchenberg, M.; Martins, D. E.; Luciano, R. P.; Puertas, E. B.; Del Curto, D.; Schmidt, B.; de Souza Oliveira, A. B. \& Faloppa, F. Histochemical analysis of paraspinal rotator muscles from patients with adolescent idiopathic scoliosis: a cross-sectional study. Medicine (Baltimore), 94(8):e598, 2015.

Wang, H. F.; Shen, J. X. \& Qiu, G. X. Effects of orthopedic surgery on the correlation between sagittal spinal curve and pelvis in adolescent idiopathic scoliosis. Chin. J. Spine Spinal Cord, 19(8):564-7, 2009.

Wang, H.; Sun, Y. P. \& Ding, W. Y. Relationship between pelvic incidence and sagittal-pelvic sagittal balance in patients with degenerative scoliosis. Chin. J. Clin. Anat., (4):281-6, 2015.

Wang, Q.; Lei, Z. J. \& Ma, Z. H. Advances in imaging evaluation of adolescent idiopathic scoliosis. Chin. J. Rehabil. Theor. Pract., 23(11): 1304-7, 2017.

Weinstein, S. L.; Dolan, L. A.; Wright, J. G. \& Dobbs, M. B. Effects of bracing in adolescents with idiopathic scoliosis. N. Eng. J. Med., 369(16):1512-21, 2013

Ye, F.; Hu, J. X. \& Shi, J. X. The study and significance of preoperative and postoperative sagittal spinal-pelvic parameters in adolescent idiopathic scoliosis. Orthop. J. China, 24(9):845-50, 2016.

Yong, Q.; Zhen, L.; Zezhang, Z.; Banqping, Q.; Feng, Z.; Tao, W.; Jun, J.; $\mathrm{Xu}, \mathrm{S}$.; Xusheng, Q.; Weiwei, M.; et al. Comparison of sagittal spinopelvic alignment in Chinese adolescents with and without idiopathic thoracic scoliosis. Spine (Phila Pa 1976), 37(12):E714-20, 2012.

Zapata, K. A.; Wang-Price, S. S.; Sucato, D. J. \& Dempsey-Robertson, M. Ultrasonographic measurements of paraspinal muscle thickness in adolescent idiopathic scoliosis: a comparison and reliability study. Pediatr. Phys. Ther., 27(2):119-25, 2015.

Zhu, Z.; Xu, L.; Zhu, F.; Jiang, L.; Wang, Z.; Liu, Z.; Qian, B. P. \& Qiu, Y. Sagittal alignment of spine and pelvis in asymptomatic adults: norms in Chinese populations. Spine (Phila Pa 1976), 39(1):E1-6, 2014.
Corresponding author:

$\mathrm{Li}$ Xiaohe and Xiaohe Li

Department of anatomy, Basic medical college

Inner Mongolia Medical University

Jinshan Economic Development Zone

Huhhot 010110

Inner Mongolia

CHINA

E-mail:798242742@qq.com

\author{
Corresponding author: \\ Zhijun Li \\ Department of anatomy \\ Basic medical college \\ Inner Mongolia Medical University \\ Jinshan Economic Development Zone \\ Huhhot 010110 \\ Inner Mongolia \\ CHINA
}

E-Mail:13904717040@qq.com

Received: 09-07-2019

Accepted: 05-09-2019 